\title{
ANÁLISE DA SEQUÊNCIA DISCURSIVAS NA MENSAGEM DO PRESIDENTE DO BRASIL TRANSMITIDA ONLINE PELA EMISSORA JOVEM PAN NO PROGRAMA RADIOFÔNICO OS PINGOS NOS IS
}

\section{ARTIGO ORIGINAL}

MALDONADO, Gabriel Orlando Quiñones ${ }^{1}$

MALDONADO, Gabriel Orlando Quiñones. Análise da sequência discursivas na mensagem do presidente do Brasil transmitida online pela Emissora Jovem Pan no programa radiofônico Os Pingos nos Is. Revista Científica Multidisciplinar Núcleo do Conhecimento. Ano 05, Ed. 10, Vol. 20, pp. 135-143. Outubro de 2020. ISSN: 2448-0959, Link de acesso: https://www.nucleodoconhecimento.com.br/letras/sequencia-discursivas

\section{RESUMO}

O presente artigo baseia-se na área da Sociolinguística Interacional e é o resultado da análise da sequência discursiva de cortesia ou de descortesia na mensagem presidencial do presidente do Brasil, Bolsonaro. Coletou-se como referência o corpus oral constituído pela interação oral do presidente com os repórteres da Emissora Jovem Pan do programa radiofônico Os Pingos nos Is na live semanal em 28 de maio de 2020. As mensagens discursivas usadas pelos mandatários políticos são

1 Pós-doutor em Educação com investigação em Sociolinguística Musical Brasileira pela Universidade Virtual de Estudos Superiores - UNIVES no México (2020); Doutor em Ensino da Língua Portuguesa pela Bircham Internacional University em Madrid Espanha (2018); Mestre em Línguas, Culturas e Sociedades em Ambientes Multilíngues - Francês Língua Estrangeira pela “Université des Antilles” em Martinica (M1-2016 / M2-2018); Pós-graduado (Especialização) em Estudos de Língua Portuguesa: Investigação e Ensino pela Universidade Aberta de Portugal (2014): Graduado em Línguas Modernas, habilitação em Português e Francês, pela Universidad de Puerto Rico - Recinto de Río Pedras (2009). 
mensagens espalhadas a um público imediato e de fácil acessibilidade tanto como a uma sociedade internacional. Os políticos apresentam as suas mensagens ao povo tendo a capacidade do que o seu discurso seja transmitido com cortesia ou descortesia. Na maioria dos discursos ou entrevistas políticas, eles tendem a quebrar a ordem interacional devido à evasão de perguntas. Os políticos lidam com as respostas que os destinatários querem saber, respondendo de outro ponto que o favoreça e não o prejudique politicamente. Este artigo teve como objetivo analisar a sequência discursiva de cortesia ou de descortesia na mensagem presidencial que ressaltou a temática da pandemia do coronavirus. A análise revela que a ordem e o equilíbrio temático foram mantidos perante o desenvolvimento da interação oral no programa dos Pingos Nos Is da Jovem Pan.

Palavras-chave: Sociolinguística Interacional, sequência discursiva, discurso político, cortesia, descortesia, COVID-19.

\section{INTRODUÇÃO}

O discurso requer uma ordem interacional que seja sempre educada, decente e respeitada, não importa quão simples e confiáveis sejam com aqueles com quem interacionam. A interação deve ter intenções saudáveis de produzir uma conversa séria e apropriada. Sob nenhuma circunstância, no campo profissional, deve-se referir às pessoas pelo apelido, assim pode-se manter o respeito e a interação formal do discurso. O conhecimento adquirido baseado nas leituras de Gumperz são um ótimo contributo para a compreensão das diferentes interações sociais que ocorrem diariamente na nossa vida profissional ou no nosso trabalho.

Segundo Gumperz (1982, p. 43),

O conhecimento adquirido lexicamente de expressões idiomáticas, saudações, aberturas e fechamentos de conversas, bem como o conhecimento de categorias sociais de palestrantes e audiências e de normas comportamentais relevantes, também desempenham um papel essencial. Examinando os resultados das trocas conversacionais e entrevistando os participantes para determinar as percepções de pistas verbais e as suposições sociais subjacentes a seus julgamentos, é 
possível obter dados empíricos sobre a interação de fatores sociais e gramaticais no comportamento verbal.

Os recursos disponíveis contribuem para a compreensão das interações discursivas e para conhecer melhor o ponto de partida das diferentes interações. $\mathrm{Na}$ esfera profissional, os professores, os linguistas e os pesquisadores, com esses recursos fornecidos pela Sociolinguística Interacional, podem entender melhor aos seus interatuantes. Além disso, conseguir a implementação das boas práticas de interação conversacional. Segundo Goffman (1961, p. 81), "to be awkward or unkempt, to talk or move wrongly, is to be a dangerous giant, a destroyer of worlds."

\section{RITUAIS VERBAIS E CORTESIA: MANUTENÇÃO OU ALTERAÇÃO DA ORDEM INTERACIONAL}

A cortesia é a base de toda comunicação. Quando se usa as palavras como meio de comunicação, pode-se incluir nessa transmissão grande parte da essência pessoal; portanto, é importante usar a cortesia como um dos valores universais. $\mathrm{Na}$ comunicação escrita, poder-se-ia complicar com o processo de transmissão das diferentes emoções, já que o texto está subordinado a interpretações individualizadas. Não entanto, seja verdade que a comunicação escrita é importante, a mesma relevância tem a interação conversacional. As interações com um objetivo geral devem ter um processo de análise prévia, no qual se internalize; o que é dito, a quem é dirigido e as repercussões da mensagem das palavras interatuadas. Muitas vezes, cumprimentamos por compromisso social, mas essas saudações não se destinam a gerar uma interação para a manutenção de uma conversa formal ou prolongada.

As palavras de cortesia, incluídas no discurso, devem ter um tom que descreva a emoção que carrega essa intenção específica. Os rituais verbais e de cortesia podem variar de acordo com o cenário em que o locutor e o interlocutor estão desenvolvendo a interação conversacional. A implementação da cortesia pode ser espontânea e natural ou pode ser um ato de reação a uma situação inesperada. Um exemplo muito simples de implicar um ato de cortesia diante de uma situação inesperada poderia ser a seguinte: quando alguém vai a um funeral de uma pessoa conhecida, mas não 
conhece aos familiares. Desde a primeira intenção, a pessoa sabe que a situação em que está se desenvolvendo é dolorosa e triste, e onde as outras pessoas presentes precisam de uma interação reconfortante. Tendo nisso em mente para não ser descortês, começa-se a selecionar palavras de cortesia que satisfaçam o que o ambiente exige. Quando, pelo contrário, encontra-se na mesma situação, com a única diferença de que o falecido era uma pessoa conhecida, as palavras de cortesia começam a fluir naturalmente projetadas pelas emoções pessoais.

\section{ANÁLISE DE SEQUÊNCIAS DISCURSIVAS DE CORTESIA E DE DESCORTESIA}

Analisa-se a transmissão do programa Pingos Nos Is da emissora Jovem Pan. Essa transmissão foi feita ao vivo no dia 28 de maio de 2020. Este programa radiofônico faz parte da emissora Jovem Pan e faz as retransmissões no Youtube. O programa foi apresentado por um dos locutores principais, Vitor Brown. Os outros três locutores fizeram o trabalho de entrevistadores; o Augusto Nunes, o José Maria Trindade e o Guilherme Fiúza. O programa sempre abre o espaço para fazer a transmissão da mensagem do presidente Jair Bolsonaro ao país.

Segundo Gumperz e Cook-Gumperz (1996, p. 10),

a tarefa inicial na análise é basicamente etnográfica, de coletar instâncias reais de situações interativas contendo todas as evidências internas para documentar os resultados. Gravações de reuniões públicas ou transmissões públicas no local fornecem uma boa primeira fonte de materiais. Como muitas vezes é impossível coletar as informações básicas necessárias para as etapas posteriores da análise, também é necessário um trabalho de campo.

Nesse dia, fizeram a mensagem presidencial ao vivo e foi conduzida pelo elenco de locutores acima mencionados. A ordem interacional dessa transmissão esteve dentro das boas práticas dos procedimentos discursivos organizados pela emissora e executados pelos locutores. Segundo Almeida (2008, p. 8),

no quadro interacional constituído pelos intervenientes das conversas de rádio, verificamos que, neste contexto interativo e interlocutivos, os 
participantes acionam um sistema de práticas, de convenções sociais e de regras de procedimentos discursivos que organizam o fluxo temático das interações.

\subsection{CORPUS DA ANÁLISE DE INTERAÇÃO}

Tema: Exclusivo: Jair Bolsonaro fala a Os Pingos nos Is durante live semanal

Data: 28 de maio de 2020

Apresentador: Vitor Brown

Entrevistadores: Augusto Nunes, José Maria Trindade e Guilherme Fiúza.

Entrevistado: O Presidente Jair Bolsonaro

\subsubsection{PRIMEIRA ANÁLISE INTERAÇÃO}

Apresentador - "Augusto quer fazer a primeira pergunta presidente na escuta".

Augusto - "Faço! Faço! Presidente, o nosso Pedro Guimarães esqueceu de... o vice-presidente de pessoa jurídica da caixa econômica já foi o Geddel Vieira Lima no governo Dilma. Então, já deve ter feito ou tentado fazer algum trabalho lá né! Eu queria perguntar o presidente o seguinte: ê... os grandes os grandes epicentros da pandemia no brasil, são estados governados por adversários do senhor".

Presidente - "Augusto se você sabe que o supremo tribunal federal decidiu que quem, (pausa) fecha ou não começa, são os estados e municípios. Eu gostaria de poder participar é disso tudo então que o supremo de se diz que cada município decidisse o que fazer porque fica em alguns locais governador, governador brigando com, com o prefeito tá! Então essa abertura tá tarde. (...)

Apresentador - "Presidente, quem vai fazer a pergunta agora é o Guilherme Fiúza que se juntou a nossa equipe aqui dos Pingos Nos Is nessa semana estreou na segunda-feira vai fazer agora a próxima pergunta".

Guilherme - "Boa noite presidente. É bom, seguindo o assunto puxado pelo Augusto Nunes. (...) Acredito que o governo terá que fazer um avanço não é uma aceleração o aprofundamento das suas reformas né 
eu sei que isso é assunto do posto Ipiranga (risos do presidente). Mas eu queria perguntar aqui ao senhor, se temos algumas medidas no horizonte sobre esse tipo de aprofundamento, reforce, certamente o governo fará, e se há algo na linha de ampliação de programa de privatização de estatais no brasil".

Presidente - "Começamos justo, obrigado pela oportunidade. Começando no final (...)"

Nesta primeira análise, o Guilherme respeita a ordem conversacional da entrevista. Ele se apresenta e diz boa noite. Em seguida, na continuação do seu discurso, o Guilherme falou sobre o "posto Ipiranga". Então, o presidente e a sua equipe de gabinete se entreolharam e riram, já que a Ipiranga é uma empresa brasileira de combustível. Segundo Notícias UOL, "o termo "Posto Ipiranga" foi dado por Bolsonaro ao ministro, ainda durante a campanha eleitoral em 2018, para defini-lo como o auxiliar de todas as respostas para a economia em um eventual governo." O presidente toma a palavra depois que o Guilherme Ihe fez a pergunta. Em resposta, o presidente agradece a oportunidade de lhe responder. Com essa expressão do presidente, vemos novamente que os parâmetros de cortesia foram respeitados. Nas interações conversacionais em entrevistas de rádios interativas, deve haver um consenso entre os locutores e os interlocutores. O locutor principal permite a interação entre outros locutores e, do mesmo modo, cordialmente, entre o presidente. Segundo Goffman (1959, p. 10), "I will refer to this level of agreement as a working consensus."

\subsubsection{SEGUNDA ANÁLISE INTERACIONAL}

Presidente: "vão pedir o intervalo, e que eu respeito o intervalo de vocês..."

Apresentador: "é isso aí presidente a gente vai fazer um... (o presidente interrompe)

Presidente: "vou tomar um copo de leite no intervalo". (risos)

Apresentador: "beleza, combinado! É um minuto e 20 de intervalo não vai passar disso está presidente a gente tem que fazer esse intervalo é compromisso comercial então a gente faz o intervalo rapidinho, daqui a pouco eu tô uma conversa com o presidente Jair Bolsonaro ao vivo aqui, vamos lá!" 
Nesta segunda análise, o presidente percebe o aviso no monitor de que um intervalo está chegando e dá a palavra ao apresentador. O presidente explica que ele respeita o intervalo. Nesta seção, vê-se que ele respeita as regras de ordem interacional que todos devem ter no programa. $O$ apresentador retoma rapidamente a palavra dizendo "beleza, combinado." Já que o presidente tinha interrompido para dizer que ia tomar um copo de leite no intervalo. O tempo do intervalo já estava anunciado e o apresentador precisa passar aos compromissos comerciais.

Em outro ponto de vista, o ato de expressar que ele tomaria um copo de leite nos comerciais, enquanto ria com a sua equipe, é percebido como sarcasmo. Embora todos riram da expressão, transformando a atmosfera com algum humor, você poderia entender que era com alguma outra intenção. Segundo Rocha (2020) na entrevista feita à Adriana Dias, diz que ela é doutora em antropologia social pela Unicamp (Universidade Estadual de Campinas) e que há anos pesquisa o fenômeno do nazismo, há uma referência clara entre o episódio e o neonazismo. "O leite é o tempo todo referência neonazista. Tomar branco, se tornar branco. Ele vai dizer que não é, que é pelo desafio, mas é um jogo de cena, como eles sempre fazem", declarou à Fórum.

Eles poderiam transmitir outra mensagem como, por exemplo, como o programa ia deixar o presidente esperando por anúncios comerciais, ou como por um intervalo deveria ficar na espera para poder continuar com o seu discurso político-presidencial.

Também, Duarte (2005, p. 294-295), diz que

o locutor e alocutário partilham saberes e crenças anteriores ao momento em que comunicam e, se isso é valido para as trocas verbais entre atores que são políticos, também o é para o jornalista que escreve um texto e os leitões que o leem.

Nesse trecho, houve uma alteração à ordem interacional pela causa do mesmo presidente do Brasil.

Segundo Fonseca (1992, p. 48), 
a compreensão do texto desenvolve-se na base desta interação entre o verbalizado e o universo de conhecimento do receptor. A captação do sentido global do texto - que envolve, como se viu, a captação das conexões microestruturais e macroestruturais desenhadas no seu espaço - depende da capacidade que revele o receptor de ligar os fatos, os acontecimentos...

\subsubsection{TERCEIRA ANÁLISE INTERACIONAL}

Apresentador: Boa, de volta. Feito o nosso intervalo estamos de volta aqui com presidente Jair Bolsonaro entrevista ao vivo exclusivo aqui para você que acompanha os Pingos Nos Is. Acho que o presidente já tomou o leite aí que ele ia tomar. Tá, tá ouvindo a gente já né presidente, tá tudo ok aí né.

Presidente - Acho que voltou.

Apresentador - Então vou fazer a próxima pergunta para o presidente. Queria falar o seguinte presente, de agora agora pouco na ... tá ouvindo o presidente? Mas que ele tá fazendo um gesto ali não sei se ela ainda tá

Presidente - Tá ok, tá ok.

Apresentador - Tá ok, beleza. Vamos lá então. o presidente agora há pouco na live o senhor tava falando sobre notícias falsas ou em precisa sair que circulam na imprensa trouxe vários exemplos quero trazer mais uma aqui para que o senhor diga para gente se procede ou não.

Ao voltar do intervalo, o apresentador retomou o discurso e disse "acho que o presidente já tomou o leite aí que ele ia tomar." O apresentador retomou a palavra com essa frase, implementando uma estratégia discursiva de humor. Entretanto, o presidente não tinha percebido que tinha voltado à transmissão ao vivo. Segundo Almeida (2010a, p. 7),

Em segmentos de maior polemicidade, ocorrem ainda atos mais ameaçadores das faces do auditório menos adequados às convenções sociais de cortesia que constrangem o locutor de rádio a produzir atos com o valor ilocutório de aviso ou de conselho que coocorrem com a realização de estratégias discursivas de humor.

\section{CONCLUSÃO}


Nos estudos linguísticos e na sociolinguística interacional, é essencial aprender atos de cortesia e descortesia. Pode-se considerar muito importante a inclusão desses estudos, não apenas para estudos avançados, mas também para estudantes de português como língua estrangeira. Manter a ordem interacional é essencial para evitar mal-entendidos quando se trata de comunicação locutor-interlocutor. O conhecimento e o bom uso das estratégias discursivas como os atos de cortesia nas nossas interações poderiam evitar contraposições entre os interatuantes. Esse ato de cortesia poderia suprimir alguma confusão ao colocar em prática as habilidades discursivas. Do ponto de vista da Pragmática e da Sociolinguística Interacional, identifico que nos diferentes trechos analisados acima, as estratégias de cortesia foram usadas na interação discursiva entre os diferentes interlocutores (locutor principal, locutores secundários - entrevistadores, interlocutor - entrevistado).

$\mathrm{Na}$ maioria dos discursos ou entrevistas políticas, eles tendem a quebrar a ordem interacional devido à evasão de perguntas. Os políticos lidam com as respostas que os destinatários querem saber, respondendo de outro ponto que o favoreça e não o prejudique politicamente. O 'envolvimento conversacional' é a interação de um mínimo de duas pessoas (locutor e interlocutor), transmitindo ou recebendo uma variedade de informações de interesse recíproco. Na entrevista feita ao presidente mostrou-se o envolvimento conversacional, constituindo-o como um interativo e ideal na hora de fazer análises e comparações dos termos linguísticos estudados neste seminário. Finalmente, comprovando a análise da ordem interacional, a ordem e o equilíbrio temático foram mantidos perante o 'envolvimento conversacional' no programa dos Pingos Nos Is da Jovem Pan.

\section{REFERÊNCIAS}

ALMEIDA, Carla Aurélia de. (2008) "O 'envolvimento conversacional' no momento de desenvolvimento de interacções verbais na rádio: sequências de actos ilocutórios e 'estratégias de alinhamento' em programas de rádio específicos." In Textos selecionados. XXIII Encontro Nacional da Associação Portuguesa de Linguística, organizado por Sónia Frota e Ana Lúcia Santos. p. 7-21. Lisboa: Colibri. ISBN 978972-96615-1-8. 
ALMEIDA, Carla Aurélia de. (2010a) “(...) é um rapaz cheio de sorte, digo-lhe já (risos)": o humor como estratégia discursiva de mitigação do conflito (potencial) em interacções verbais na rádio in Brito et al., Textos Seleccionados, XXV Encontro Nacional da Associação Portuguesa de Linguística, Porto, APL. p. 127-142,

DUARTE, Isabel Margarida. (2005) “Falar claro a mentir" in Dar a Palavra à Língua Homenagem a Mário Vilela, Porto, FLUP. p. 291-299.

FONSECA, J. (1992) Coerência e coesão nas unidades linguísticas. In J. Fonseca (Org.), Linguística e texto / discurso - teoria, descrição, aplicação. p.7-104. Lisboa: Ministério da Educação / Instituto de Cultura e Língua Portuguesa. Disponível em: $<$ http://cvc.instituto-camoes.pt/conhecer/biblioteca-digital-camoes/explorar-porautor.html?aut=129> Acesso em 10 jul. 2020.

GOFFMAN, Ervin. (1961a) Encounters. Indianapolis, Indiana: Bobbs Merrill.

GOFFMAN, Ervin. (1959) Presentation of Self in Everyday Life. New York: Doubleday Anchor.

GUMPERZ, John. (1982) Discourse strategies. Cambridge, Cambridge University Press.

GUMPERZ, John e COOK-GUMPERZ, Jenny. (1996) (ed.) - Language and social identity. New York, Cambridge University Press, p. 1-21.

OS PINGOS NOS IS. (2020) EXCLUSIVO: Jair Bolsonaro fala a Os Pingos nos Is durante live semanal. 28 de maio de 2020. Disponível em: $<$ https://www.youtube.com/watch?v=QAkuWmRckgc> Acesso em 10 jul. 2020.

POSTO IPIRANGA: <https://postoipiranganaweb.com.br/> Acesso em 10 jul. 2020.

NOTÍCIAS UOL. (2020) "Mais que Posto Ipiranga. Um irmão", diz Jair Bolsonaro sobre Paulo Guedes. Em São Paulo 24/03/2020 20h38. Disponível em $<$ https://noticias.uol.com.br/politica/ultimas-noticias/2020/03/24/mais-que-posto- 
ipiranga-um-irmao-diz-jair-bolsonaro-sobre-paulo-guedes.htm?cmpid=copiaecola> Acesso em 10 jul. 2020.

ROCHA, Lucas. (2020) Copo de leite: Bolsonaro usa símbolo nazista de supremacia racial em live. 29 de maio de 2020. Revista Fórum. Disponível em: $<$ https://revistaforum.com.br/politica/copo-de-leite-bolsonaro-usa-simbolo-nazista-desupremacia-racial-em-live/> Acesso em 10 jul. 2020.

SIMONIN, O. (2010) "(Im)politesse, coopération et principes d'inférence", Lexis, Spécial issue No. 2, pp. 21-35. Disponível em: <http://lexis.univlyon3.fr/IMG/pdf/Lexis_special_2__Simonin.pdf> Acesso em 10 jul. 2020.

Enviado: Outubro, 2020.

Aprovado: Outubro, 2020. 